\title{
Gallstone ileus, surgical management review
}

\author{
íleo biliar, revisión del manejo quirúrgico
}

\author{
Marcos I. Salazar-Jiménez" * Javier Alvarado-Durán², Mónica R. Fermín-Contreras³, \\ Fernando Rivero-Yáñez ${ }^{1}$, Arianne I. Lupian-Angulo ${ }^{1}$ and Antonio Herrera-González ${ }^{1}$ \\ ${ }^{1}$ Department of General Surgery; ${ }^{2}$ Department of General Surgery, Sanatorio Durango; ${ }^{3}$ Endoscopy Department. Hospital Central Norte PEMEX, \\ Mexico City, Mexico
}

\begin{abstract}
Background: Gallstone ileus (GI) represents a rare cause of mechanical intestinal occlusion, which is caused by the impaction of a gallstones at the gastrointestinal tract, being most frequently the terminal ileum; its etiology is due to the passage of a calculum through a biliary-enteric fistula. Due to its low incidence, diagnostic suspicion and adequate initial surgical treatment are essential for an adequate clinical evolution. Objective: A bibliographic review on the current surgical management of GI was carried out and exemplified by the presentation a clinical case. Clinical case: 78-year-old male with bowel obstruction, upon undergoing a CT scan, a gallstone at the level of distal ileum is displayed, therefore, an exploratory laparotomy (ex lap) is performed with enterotomy and extraction of the calculus. The patient bestowed adequate postoperative clinical evolution, and the presence of a cholecystoduodenal fistula is documented by an upper endoscopy. Discussion: Gl represents an uncommon pathology, however, there is discrepancy in the literature regarding the initial surgical management, especially in whether or not a biliary procedure should be associated with emergency enterolithotomy. Conclusion: Gl is associated with complications secondary to diagnostic delay and its late surgical resolution, although the initial treatment is aimed at resolving the intestinal obstruction through enterotomy and gallstone extraction, there is controversy regarding the preferred time for cholecystectomy and repair of biliary-enteric fistula, being the two-stage surgery the surgical procedure of choice, especially in patients with a high risk of complications.
\end{abstract}

KEY WORDS: Gallstone ileum. Surgical management. Cholecystoduodenal fistula. Intestinal occlusion.

\section{Resumen}

Antecedentes: El íleo biliar (IB) es una causa poco frecuente de oclusión intestinal mecánica, causado por la impactación de un cálculo biliar en el tubo digestivo, siendo la localización más frecuente el íleon terminal; se debe al paso de un cálculo a través de una fístula bilioentérica. Debido a su baja incidencia, la sospecha diagnóstica y el tratamiento quirúrgico inicial adecuado son de gran importancia para la evolución clínica. Objetivo: Realizar una revisión bibliográfica sobre el manejo quirúrgico actual del IB y ejemplificarlo mediante la presentación de un caso clínico. Caso clínico: Varón de 78 años con cuadro de oclusión intestinal, con presencia de cálculo biliar en el íleon distal por tomografía. Se realiza laparotomía exploradora con enterotomía y extracción del cálculo. Cursa con adecuada evolución posquirúrgica, documentándose fístula colecistoduodenal por panendoscopia. Discusión: El IB es una patología poco común, por lo cual existe discrepancia en cuanto al tipo de manejo quirúrgico ideal, sobre todo en si se debe o no asociar un procedimiento biliar a la enterolitotomía de urgencia. Conclusión: El IB se asocia a complicaciones secundarias al retraso diagnóstico y a una mala elección de la técnica quirúrgica inicial. Si bien el tratamiento está encaminado a resolver la obstrucción intestinal mediante enterotomía y extracción del cálculo biliar, existe controversia en cuanto al tiempo preferido para realizar la colecistectomía y la reparación de la fístula

\author{
Correspondence: \\ *Marcos I. Salazar-Jiménez \\ Valladolid 40 interior $304 \mathrm{~A}$ \\ Col. Roma norte, Del. Cuauhtémoc \\ C.P. 06700, Ciudad de México, México \\ E-mail: marcos.salazarj@gmail.co
}

Date of reception: 01-04-2018

Date of acceptance: 20-04-2018

DOI: 10.24875/CIRUE.M18000026
Cir Cir. 2018;86:163-167

Contents available at PubMed www.cirugiaycirujanos.com 
bilioentérica, siendo la cirugía en dos tiempos el procedimiento quirúrgico de elección, sobre todo en pacientes con alto riesgo de complicaciones.

PALABRAS CLAVE: Íleo biliar. Manejo quirúrgico. Fístula colecistoduodenal. Oclusión intestinal.

\section{Introduction}

Gallstone ileus $(\mathrm{Gl})$ is described as a mechanical intestinal obstruction caused by impaction of one or more gallstones on any part of the digestive tract, mainly in the small intestine, with the most common site being the distal ileum ${ }^{1}$. The etiology is secondary to the passage of a gallstone from the bile ducts or the gallbladder to the gastrointestinal tract through an enterobiliary fistula (with the most common cause being cholecystoduodenal fistula), which is formed by the presence of recurrent episodes of acute cholecystitis or secondary to Mirizzi syndrome, where there is chronic perivesicular inflammation that generates adherences between the bile duct and the gastrointestinal tract, and subsequent to that, the pressure exerted by the gallstone causes necrosis of the vesicular wall, thus eroding it and causing bilioenteric communication ${ }^{2-4}$.

Gl accounts for 0.3 to $0.5 \%$ of cholelithiasis complications, with an incidence of $3 / 100,000$ hospitalizations associated with biliary pathology, and is more common in the female gender at a 3.5:1 ratio, with higher incidence in people older than 65 years. It accounts for $0.5 \%$ of the causes of small bowel obstruction, affecting mainly patients older than 65 years with multiple comorbidities, and with a mortality 5 to 10 fold higher than the rest of the causes of small bowel obstruction ${ }^{5,6}$.

The size of the stone is significant to triggering the disease. It should measure at least $2 \mathrm{~cm}$ in diameter (2.5 $\mathrm{cm}$ on average) to cause obstruction $(90 \%$ of cases). The site where the calculus is lodged will induce different clinical scenarios, including Barnard's syndrome, where the stone obstructs the ileocecal valve, manifesting as a classic intestinal occlusion, sometimes accompanied by jaundice (in less than $15 \%)$, characterized by abdominal distension, pain, vomiting, absence of peristalsis, constipation or obstipation. On the other hand, there is the Karewsky syndrome, which is characterized by chronic presence of intermittent abdominal pain, caused by the passage of gallstones to the intestine. Involvement of the colon is much rarer, which is associated with sites of stenosis or narrowing secondary to inflammatory bowel disease ${ }^{2,7-9}$.
Diagnostic suspicion is of paramount importance for timely management. Clinically, the Mordor triad is described, which includes known cholelithiasis diagnosis, clinical signs of acute cholecystitis and data consistent with intestinal obstruction. As part of the paraclinical tests, Rigler's triad is described in abdominal $X$-ray, which involves the presence of radiopaque stones (less than $10 \%$ of cases), pneumobilia (Gotta-Mentschler sign) and intestinal loop distension, with the diagnosis being established in the presence of two of these three radiological signs. When adding gallstone position change in a second radiograph, Rigler's tetrad is completed, which has higher diagnostic sensitivity. The Petren sign corresponds to the passage of contrast medium into the biliary tract ${ }^{8-10}$.

Computed tomography with contrast medium is considered the method of choice for the diagnosis of GI, with a sensitivity higher than $90 \%$. It is important to rule out the most common causes of intestinal occlusion, such as adherences, incarcerated/strangulated hernia, abdominal tumor, volvulus, etc. ${ }^{7,8,11}$.

Gl treatment is aimed at resolving intestinal obstruction, after patient stabilization. Surgical treatment remains the management of choice in these patients and is divided in two stages ${ }^{1,3,8}$ :

- Stage 1: laparotomy with longitudinal enterolithotomy at the antimesenteric border, after milking the stone in the proximal area, with transversal closure being performed to avoid stenosis. Milking of the gallstone to the colon is not recommended because it is associated with mucosal injury and rupture of the serosa, which may go unnoticed ${ }^{1,2}$. A systematic examination of the entire intestine is carried out in search of gallstones, which can be found in $3-16 \%$ of cases, and can be extracted using the same enterotomy. Most cases of Gl relapse are associated with unidentified stones on initial laparotomy. In selected patients, a laparoscopic approach with eventration of the compromised intestinal segment can be performed, which entails lower morbidity and shorter recovery time; however, it is considered a technical challenge due to the degree of difficulty ${ }^{1,2}$.

- Stage 2: depending on patient risk factors, one of the following options is chosen: 
- Observation in those patients at high risk (ASA III or IV), in shock, with multiple adherences and important intestinal inflammation. In case of GI relapse (4.7-17\%), a laparoscopic cholecystectomy should be performed when patient conditions allow.

- Patients at low risk (ASA I, II) can undergo cholecystectomy and biliary fistula closure the at the same surgical time of enterolithotomy with common bile duct exploration if warranted (one-stage surgery), which reduces recurrence, prevents malabsorption and weight loss, avoids cholecystitis and cholangitis, and decreases the risk of gallbladder carcinoma ${ }^{1,2,8,12}$.

On occasions, endoscopic management with mechanical fragmentation lithotripsy can be used as an alternative for patients who are not candidates for surgical management ${ }^{12,13}$.

This is a pathology that mainly affects older adults, who usually have multiple comorbidities, with an estimated mortality of 4.5 to $25 \%$, which is 5 to 10 -fold higher in comparison with the rest of small bowel obstruction causes ${ }^{1,2}$.

\section{Clinical case}

This is the case of a 78-year-old male patient who was admitted by referral from the emergency department. He had a 24-hour history of signs and symptoms characterized by colicky abdominal pain at the mesogastrium, with an intensity of 7 out of 10 on the visual analogue scale and diffuse irradiation to the rest of the abdomen, which was associated with intolerance to the oral route and with the presence of vomiting, initially of gastric content, but that later became fecaloid. He reported having had a decreased-consistency stool prior to his admission.

Relevant past medical history included high blood pressure diagnosed 16 years prior on management with amlodipine ( $5 \mathrm{mg} / 24 \mathrm{~h})$, candesartan $(8 \mathrm{mg} / 12 \mathrm{~h})$ and metoprolol (25 mg/24 h), and hypothyroidism diagnosed 15 years prior and managed with levothyroxine $(100 \mathrm{mg} / 24 \mathrm{~h})$. He had undergone conventional appendectomy 6 years prior. He denied past history of trauma, transfusions and drug addiction. He referred having been diagnosed with cholelithiasis 6 years prior due to apparent acute cholecystitis.

Relevant findings on physical examination included abdominal distention with generalized pain with medium pressure and deep palpation, predominantly in the mesogastrium, without muscle resistance or
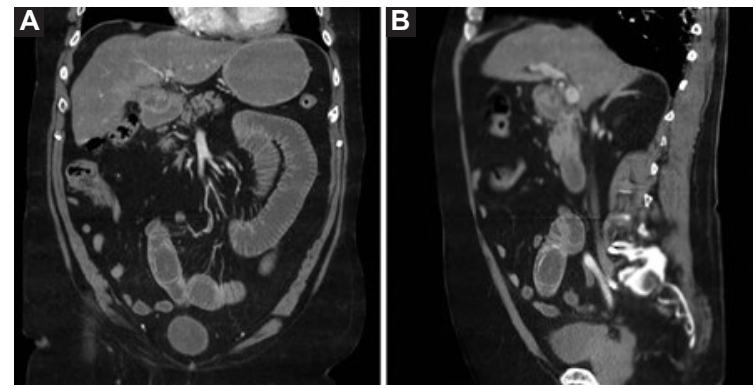

Figure 1. Abdominal tomography, where a $2.5 \times 2.4 \times 4.4-\mathrm{cm}$ image is observed at the level of the jejunum. A: coronal slice. B: sagittal slice.

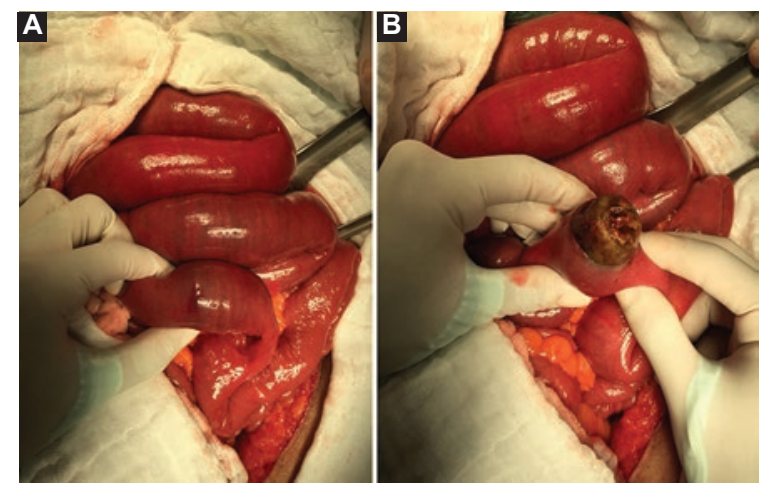

Figure 2. A: calculus in the jejunum with loop dilation at the proximal level. B: jejunum longitudinal enterolithotomy with gallstone extraction.

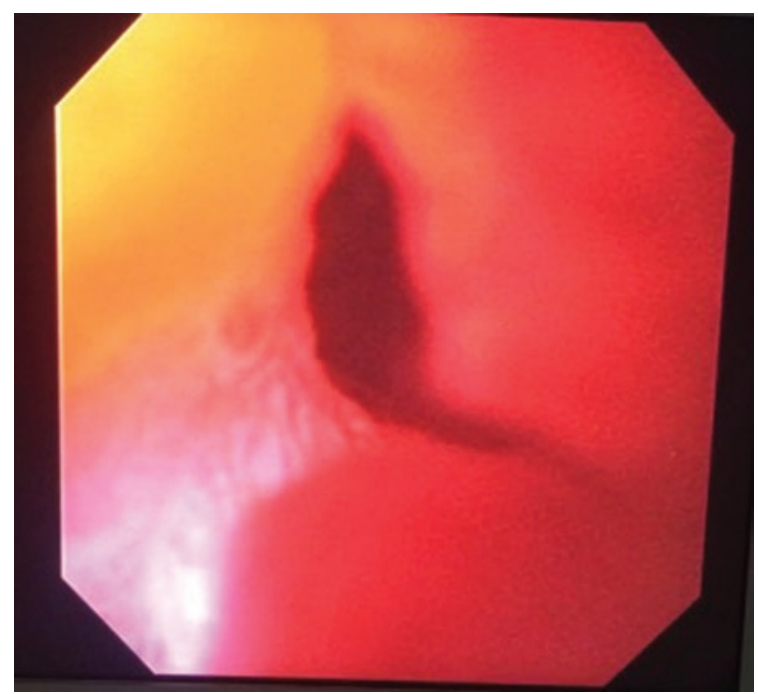

Figure 3. Control endoscopy with presence of cholecystoduodenal fistula.

data consistent with peritoneal irritation; decreased peristalsis was detected in all four quadrants.

Laboratory tests indicated a white blood cell count of $14.8 \times 10^{3} / \mathrm{mL}$, with neutrophils at $12.7 \times 10^{3} / \mathrm{mL}$; lymphocytes, $1.2 \times 10^{3} / \mathrm{mL}$; hemoglobin, $17.3 \mathrm{~g} / \mathrm{dL}$; hematocrit, $53.3 \%$; platelets, $216 \times 10^{3} / \mathrm{mL}$; creatinine, $1.22 \mathrm{mg} / \mathrm{dL}$; BUN, $20.4 \mathrm{mg} / \mathrm{dL}$; urea, $43.7 \mathrm{mg} / \mathrm{dL}$; sodium, $141 \mathrm{mEq} / \mathrm{L}$; potassium, $4.4 \mathrm{mEq} / \mathrm{L}$; and chlorine, $99 \mathrm{mEq} / \mathrm{L}$. 
GI diagnosis

Enterotomy with gallstone extraction*

(Exploratory or laparoscopic laparotom)

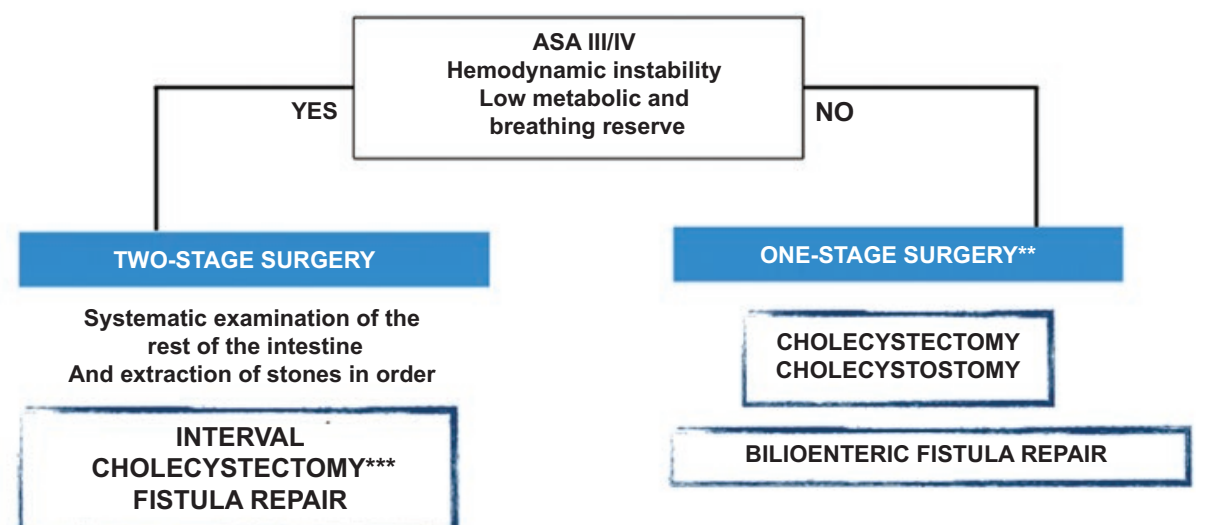

Figure 4. Gallstone ileus treatment algorithm.

A nasogastric tube was placed, with the presence of fecaloid-type output of approximately $1500 \mathrm{cc}$ being documented at the moment of placement. Contrasted abdominal tomography reported a $2.5 \times 2.4 \times 4.4-\mathrm{cm}$ heterogeneous image at the level of the ileum, which caused an up to $4.3 \mathrm{~cm}$ dilation of the small bowel loops at the level of the jejunum, probably related to $\mathrm{Gl}$, as well as presence of two similar images, smaller in size, at the level of the jejunum, not consistent with obstruction data (Fig. 1).

Exploratory laparotomy revealed the presence of a plastron of inflammatory appearance in the hepatic angle, with firm adherences of the transverse colon to the duodenum, the omentum and the Gleason capsule, without the gallbladder or the extrahepatic bile duct being able to be visualized. A gallstone of approximately 2.5 $\times 2.5 \times 4 \mathrm{~cm}$ in diameter was found at $240 \mathrm{~cm}$ from the ligament of Treitz, which caused proximal dilation of the small intestine loops, without evidence of necrosis of the wall or disruption of the intestinal serosa. A longitudinal enterotomy was performed on the antimesenteric border and the stone was extracted after proximal milking at $60 \mathrm{~cm}$ from the ileocecal valve (Fig. $2 \mathrm{~A}$ and B).

The patient had an adequate clinical evolution, tolerating the oral route 48 hours after the surgical intervention. A subsequent panendoscopy revealed the presence of a contraction scar and fistula orifice of approximately $6 \mathrm{~mm}$ in diameter, with well-defined, slightly elevated edges, with edema and hyperthermia, with a normal vascular pattern, at the level of the duodenal bulb (Fig. 3), in relation to probable cholecystoduodenal fistula.

\section{Discussion}

$\mathrm{Gl}$ is an infrequent cause of mechanical intestinal occlusion ${ }^{1,2}$. Clinical suspicion should be present in patients with abdominal pain consistent with acute cholecystitis and high intestinal occlusion, since the most common site of gallstone impaction is the distal ileum. Only patients with alterations in large intestine normal anatomy (inflammatory bowel disease, neoplasms, etc.) present with data of low intestinal occlusion due to impaction of the stone at the narrowing site $^{1,2,4}$.

Initial management of patients with $\mathrm{Gl}$ is always surgical after stabilization (adequate hydration, analgesia, hydroelectrolytic correction, etc.), and is aimed at resolving the obstruction and preventing complications such as ischemia of the intestinal wall, perforation, peritonitis and even death. Enterotomy at the anti-mesenteric border with extraction of the gallstone and transverse closure is the standard emergency management; cholecystectomy with resolution of the fistula in the same surgical act is reserved for young and clinically stable patients, when their conditions allow it, with two-step surgery with interval cholecystectomy being the most recommended approach in the majority of cases $^{3,5}$.

\section{Conclusions}

Due to its low incidence, there is no consensus setting out the rules for the management to be followed in 
patients diagnosed with GI. Although surgical resolution is known to be the standard treatment, there are different opinions regarding the type of surgery to be performed. Reisner and Cohen ${ }^{14}$ support two-stage surgical management with emergency enterolithotomy plus extraction of the stone, whereby intestinal obstruction is solved, associated with an interval cholecystectomy with cholecystoenteric fistula repair 4-6 weeks later in patients at risk of recurrence, which is associated with lower morbidity. On the other hand, Rodríguez-Sanjuán et al. ${ }^{15}$ recommend one-stage surgery, which includes a biliary technique (cholecystectomy or cholecystostomy), with closure of the fistula associated with enterolithotomy, arguing a decrease in the risk of recurrence and carcinoma of the gallbladder, with a similar mortality to that of enterolithotomy alone, especially in patients with clinical stability and low surgical risk. Endoscopic management is reserved for those patients with high surgical risk.

According to the literature review ${ }^{1,8}$, we propose the treatment algorithm shown in figure 4.

\section{Conflicts of interest}

The authors declare not having any type of conflicts of interest.

\section{References}

1. Halabi WJ, Kang CY, Ketana N, Lafaro KJ, Nguyen VQ, Stamos MJ, et al. Surgery for gallstone ileus: a nationwide comparison of trends and outcomes. Ann Surg. 2014;259:329-35.

2. Van Hillo M, van der Vliet JA, Wiggers T, Obertop H, Terpstra OT, Greep JM. Gallstone obstruction of the intestine: an analysis of ten patients and a review of the literature. Surgery. 1987;101:273-6.

3. Beltran MA, Csendes A, Cruces KS. The relationship of Mirizzi syndrome and cholecystoenteric fistula: validation of a modified classification. World Surg. 2008;32:2237.

4. Martín Pérez J, Delgado Plasencia L, Bravo Gutiérrez A, Burillo-Putze G, Martínez-Riera A, Alarcó-Hernández A, et al. [Gallstone ileus as a cause of acute abdomen. Importance of early diagnosis for surgical treatment.] Cir Esp. 2013;91:485-9.

5. Alexiou K, loannidis A, Sikalias N, Konstantinidou E, Fotopoulos A, Karanikas I, et al. Gallstone ileus: a case report and our clinic's experience. Surgical Science. 2014;5:10-4

6. Ayantunde AA, Agrawal A. Gallstone ileus: diagnosis and management. World J Surg. 2007;31:1292.

7. Beuran M, Ivanov I, Venter MD. Gallstone ileus-clinical and therapeutic aspects. J Med Life. 2010;3:365-71.

8. Keaveny AP, Afdhal NH, Bowers S. Gallstone ileus. UpToDate. Disponible en: https://www.uptodate.com/contents/gallstone-ileus.

9. Rodríguez-Hermosa Jl, Codina-Cazador A, Gironès-Vilà J, Roig García J, Figa Francesch M, Acero Fernández D. Íleo biliar: resultados del análisis de una serie de 40 casos. Gastroenterol Hepatol. 2001;24:489-94.

10. Noriega-Maldonado $O$, Bernal-Mendoza LM, Rivera-Nava JC, Guevara-Torres L. Íleo biliar. Cir Ciruj. 2005;73:443-8.

11. Doko M, Zovak M, Kopljar M, Glavan E, Ljubicic N, Hochstädter H. Comparison of surgical treatments of gallstone ileus: preliminary report. World J Surg. 2003;27:400-4

12. Seal EC, Creagh MF, Finch PJ. Gallstone ileus: a new role for abdominal computed tomography. Postgrad Med J. 1995;71:313.

13. Nuño-Guzmán CM, Arróniz-Jáuregui J, Moreno-Pérez PA, Chávez-Solís EA Esparza-Arias N, Hernández-González Cl. Gallstone ileus: one-stage surgery in a patient with intermittent obstruction. World J Gastrointest Surg. 2010;2:172-6.

14. Reisner RM, Cohen JR. Gallstone ileus: a review of 1001 reported cases. Am Surg. 1994;60:441-6.

15. Rodríguez-Sanjuán JC, Casado F, Fernández MJ, Morales DJ, Naranjo A. Cholecystectomy and fistula closure versus enterolithotomy alone in gallstone ileus. Br J Surg. 1997;84:634-7. 